\title{
Kaiser, Rom und Reich bei Prudentius
}

\author{
Christian Gnilka
}

1.

Es ist schwer, einen Autor zu verstehen - wirklich zu verstehen, der sich für eine Sache begeistert, die uns aussichtslos erscheint; der ein Ideal vertritt, das durch die Geschichte widerlegt ist; der das Ideal auf Anschauungen gründet, die uns fremd oder verkehrt anmuten; der die antiken Götter, die uns in Dichtung und Kunst als reizende Wesen begegnen, als böse Unholde will sehen lassen; der das Verbot ihres Kults als Rettung preist; der als Befreiung feiert, was modernem Toleranzdenken zuwider ist. Das alles gilt für Prudentius, der um das Jahr 400 von der ewigen Größe Roms redet; der die Einheit des Reichs feiert, da es auseinanderbricht; der am Vorabend der militärischen Katastrophen die pax Romana verherrlicht. Augustinus sagt: Kein Gut wird vollkommen erkannt, wenn es nicht vollkommen geliebt wird. ${ }^{1}$ Wenn das zutrifft: können wir den Dichter verstehen, den zu lieben uns schwer fällt?

2.

„Das Schicksal des Reichs war in einem kleinen Winkel Italiens entschieden.“ Das sind Worte Edward Gibbons. ${ }^{2}$ Er spricht von der Schlacht am Frigidus, in der Theodosius der Große über den Usurpator Eugenius und den Franken Arbogast siegte. Ihre Niederlage bedeutete das politische Ende der heidnischen resistenza. Zosimus berichtet, Theodosius sei nach dem Sieg vor den Senat in Rom getreten und habe in einer Rede die heidnischen Senatoren aufgefordert, den Götterkult aufzugeben. Zwar habe sich kein einziger dieser Senatoren überzeugen lassen, doch der Entzug der staatlichen Unterstützung des Kults, den Theodosius damals anordnete, habe den alten Riten für immer das Ende bereitet. Zosimus sieht darin den Grund für den Verfall des Reichs, versteht

1 Augustinus, De diversis quaestionibus LXXXIII, quaestio 35.2.

2 Edward Gibbon, The History of the Decline and Fall of the Roman Empire. A new edition. Vol. 3 (London, 1823), p. 451.

(C) CHRISTIAN GNILKA, 2015 | DOI 10.1163/9789004291935_011

This is an open access chapter distributed under the terms of the Creative Commons AttributionNoncommercial 3.o Unported (CC-BY-NC 3.o) License. 
also den Rombesuch des siegreichen Kaisers als epochales Ereignis. ${ }^{3}$ Diese Nachricht von einem (zweiten) Rombesuch des Theodosius wird von manchen Forschern skeptisch aufgenommen. Aber Zosimus schöpft aus Autoren, die in zeitlicher Nähe zu den Ereignissen standen, aus Eunap und Olympiodor. Außerdem wird seine Mitteilung durch einen Zeitzeugen bestätigt, der von diesen Historikern ganz unabhängig ist. ${ }^{4}$ Prudentius hat diese Senatsrede des Kaisers zum Kernstück eines Gedichtbuchs gemacht, des Ersten Buchs Contra Symmachum. Das Buch setzt den Sieg am Frigidus voraus (1.410; 462f.), ist aber noch zu Lebzeiten des Theodosius abgeschlossen, ${ }^{5}$ also vor dem 17. Januar 395. Prudentius ist Dichter, stand aber zeitweilig, wie er selbst bezeugt (Praefatio 19-21), „in der Nähe“ des Kaisers, wohl des Theodosius, gehörte vielleicht zum kaiserlichen Consistorium. Wir hören in seinen Gedichten also die Stimme eines Mannes, der aus dem Zentrum der Macht kommt. Aber es ist auch die Stimme eines Dichters, der über jene Freiheit verfügt, die man in der Antike der Poesie gewährte, ja von ihr erwartete.

\section{3.}

Das Erste Buch behandelt nach des Autors eigener Angabe (2.1-3) Entstehung und Ausbreitung des Götterkults sowie den Übergang Roms zum Christentum. Der Dichter hat diesen Stoff dramatisch gestaltet. Die Entstehung des Kults erklärt er nach der Art des Euhemeros durch Vergottung der Herrscher, sieht darin aber bereits den Ansatz des Übels, weil diese Männer böse und schlaue Betrüger gewesen seien. Seine Darstellung ist darauf abgestimmt, eine unaufhaltsam fortschreitende Verschlimmerung der Verhältnisse sichtbar zu machen, also eine Dekadenz, die in den moralischen und geistlichen Untergang mündet. Im Großen, auf der geschichtlichen Ebene, zeigt sich das durch die Ausbreitung des Kults, der von der göttlichen Verehrung der lebenden Herrscher zum Kult der verstorbenen und so zur römischen Kaiserapotheose führt, der aber in sich das Prinzip zur Ausweitung auf den Kult der Abstrakta und der

3 Zosimus, Historia Nova 4.59; vgl. 5.38.

4 Richtiges Urteil bei Alan Cameron, "Theodosius the Great and the Regency of Stilico," Harvard Studies in Classical Philology 73 (1969), 247-28o, hier 247-265, besonders 2566 .

5 Vgl. Prudentius, Contra Symmachum 1.37f. parete magistro Sceptra gubernanti. Die gelehrten Bemühungen, die beiden Bücher Contra Symmachum in den doppelten Rahmen der Zeitgeschichte und des Dichterlebens einzuspannen, haben zu verschiedenen werkanalytischen Entwürfen geführt. Vgl. Altay Coşkun, "Zur Biographie des Prudentius," Philologus 152 (2008), 294-319, hier 300, Anmerkung 19. Ich kann auf das Problem hier nicht eingehen. Ich zitiere Prudentius nach der Ausgabe von Johan Bergman, Vienna 1926 (CSEL 61). 
Elemente enthält, also zu immer tolleren Formen der Apotheose übergeht. Im Privatleben ist es die religiöse Erziehung des Kindes durch die Kultübung der Erwachsenen im Hause und den Eindruck des Staatskults in der Öffentlichkeit, die dem Menschen jede Möglichkeit nimmt, sich eines Besseren zu besinnen. Der Tiefpunkt der stufenweise fortschreitenden Depravation ist mit dem Kult der unterirdischen Gottheiten, der Hekate/Trivia und des Dis erreicht. Denn in diesen Göttern verehrt der Mensch, so sieht es der Dichter, jene höllischen Mächte, die seinen eigenen, ewigen Untergang betreiben, und jeder Gladiator, der in der Arena fällt, ist in der Sicht des Dichters ein Opfer, dargebracht jenem Höllengeist, der sich hinter dem Namen des Iuppiter infernalis verbirgt.

4.

Da nun, in dieser aussichtslosen, katastrophalen Lage, erscheint Theodosius in Rom, hält seine Rede (1.408-505) und bewirkt einen totalen Umschwung: ganz Rom, Volk und Senat, geht freudig zum Christentum über (1.506-631), nur eine kleine Minderheit des Senats, darunter Symmachus selbst, bleibt zurück (1.548; 574-577; 591f.; 624-631). Die Rede des Theodosius ist also mit Bedacht in die Komposition des Gedichts eingefügt: auf dem Höhepunkt der furchtbaren Verirrung leitet das Auftreten des Princeps die Peripetie ein. Die Peripetie ist ein Element des Dramas, setzt sich aber als künstlerisches Mittel auch in anderen Literaturformen durch. Aus der peripatetischen Geschichtsschreibung hat Livius dieses Mittel in seine Erzählkunst übernommen, und Vergils Streben nach dramatischer Gestaltung des Stoffs schließt häufige Peripetien ein. ${ }^{6}$ Öfters bewirkt die Rede bestimmter Personen den Umschwung, so das Auftreten des Consuls Servilius vor der Volksversammlung im Jahr 495 v.Chr., der in höchster Bedrohung Roms durch die Volsker das empörte Volk dazu bringt, zu den Waffen zu greifen (Livius 2.24). Aeneas vergißt bei Dido seine schicksalshafte Bestimmung, da liest ihm Merkur die Leviten (Vergil, Aeneis 4.265-276), „und unaufhaltsam drängt die Erzählung nach entgegengesetzter Richtung, zur Abfahrt des Aeneas" (Heinze). ${ }^{7}$ Von diesen Autoren hat Prudentius gelernt, das beweist sein Epos. In der Psychomachie wird die Peripetie öfters zum Zweck der Dramatisierung der Handlung eingesetzt. So läßt sich das gesamte Tugendheer von den Reizen der Luxuria berücken und ist schon bereit, sich ihr zu ergeben, da tritt Sobrietas auf und stellt dictis mordacibus (Psychomachia 349)

6 Erich Burck, Die Erzählkunst des T. Livius (Berlin, 1964²), pp. 210-18; Richard Heinze, Virgils epische Technik (Leipzig, 1914²/Darmstadt, 19574), pp. 323-26.

7 Heinze, Epische Technik, p. 324. 
die Moral der Truppe wieder her. Diese Technik hat Prudentius im ersten Buch Contra Symmachum dazu benutzt, eine große, epochale Peripetie in der Geschichte Roms zum Ausdruck zu bringen, indem er den Auftritt des Kaisers vor dem Senat als historischen Wendepunkt wirken läßt, darin dem Zosimus durchaus ähnlich, wenn auch die Bewertung des Ereignisses bei beiden nicht gegensätzlicher sein könnte. Für Prudentius führt alles, was vorhergeht, in den Abgrund hinab, alles, was folgt, führt empor zur Rettung.

\section{$5 \cdot$}

Eine Konsequenz der dramatischen Komposition ist die Konzentration der Darstellung auf einen einzigen Mann, und die Komposition ist eben gewählt, um alles Licht auf diesen Mann fallen zu lassen - dessen Name übrigens, aus metrischem Grunde, niemals genannt wird. ${ }^{8}$ Aber der panegyrische Zug des Gedichts ist nicht Selbstzweck. Formgeschichtlich bietet das Erste Buch Contra Symmachum ein Zeugnis der Gattungsmischung, gebildet aus epischen, panegyrischen und satirischen Elementen. Innerlich zusammengehalten und bewegt wird das Ganze durch das protreptische Ziel, das der Autor verfolgt. Das Buch ist ein einziger, vielgestaltiger Protreptikos, gerichtet an jene Minderheit des Senats, die, wie auch Zosimus feststellt, Roms Conversion nicht mitgemacht hat, also an Symmachus und seinen Kreis. Man hat von Eusebius gesagt, er entwickle seine Ideen als politischer Publizist und in stark rhetorischer Stilisierung. ${ }^{9}$ Das gilt in gewisser Weise auch für den Dichter. Er unterstützt die Religionspolitik seines Kaisers, und dieser Propaganda dient auch das Herrscherlob. Es geht darum, denjenigen Mann ins rechte Licht zu setzen, der durch seine Gesetze dem Götterkult ein Ende gemacht hat und der allein die Verantwortung dafür trägt (vgl. 1.14 Vir solus, cui cura fuit...eqs.). Eusebius schuf einen neuen Begriff des Tyrannen: Tyrann ist nicht nur im staatsrechtlichen Sinne der Usurpator und im moralischen der Despot, er ist zugleich im religiösen Sinne der Christenfeind. ${ }^{10}$ Prudentius gibt eine Definition, die den Begriff vertieft: Tyrannen kümmern sich nur um das gegenwärtige, irdische Wohler-

8 Der Name ließ sich nur mit Synizese dem Metrum fügsam machen, so ICUR 2 4780,1 = ILCV 1761a,1 (S. Paolo fuori le mura): Theodosius coepit, perfecit Honorius aulam und sechsmal bei Claudian. Prudentius meidet solche Synizesen bei Eigennamen, s. Christian Gnilka, Prudentiana I. Critica (Munich, 200o), pp. 262f; 348. Allerdings hat der Dichter auch die Theodosiussöhne, Honorius und Arcadius, nicht namentlich genannt.

$9 \quad$ Erik Peterson, Der Monotheismus als politisches Problem (Leipzig, 1935), p. 79.

10 Raffaele Farina, L'impero e l'imperatore cristiano in Eusebio di Cesarea (Zürich, 1966), pp. $226 f$. 
gehen, nicht, wie Theodosius, um das ewige Heil des Volks (1.22-29); denn Theodosius ist Seelsorger (1.19-21) und verwirklicht darum das platonische Ideal des Philosophen auf dem Königsthron, das freilich im christlichen Sinne aufgefaßt wird: er gehört zu den wenigen Herrschern, die „die Lehre der himmlischen Weisheit achteten" $(1.30-34) .{ }^{11}$ Und folgerichtig schließt sich an das Herrscherlob die Aufforderung, diesem Lehrer zu gehorchen (1.37 parete magistro), seine Mahnung zu beherzigen (1.38 monet), womit der protreptische Charakter des Werks von Anfang an festgestellt wird.

6.

Auch Hohn, Jammer und Empörung, die Affekte, die Prudentius mit seiner Darstellung der Götterwelt erregen will, arbeiten auf den protreptischen Zweck des ganzen Werks hin, vor allem aber die Senatsrede des Kaisers, das Herzstück des Gedichts, tritt offen für dieses Ziel ein. Sie ist ein psychagogisches Meisterstück, der Denkweise der Adressaten angepaßt, natürlich eine freie Komposition des Dichters, eine Suasorie, die den Tenor der antiheidnischen Edikte des Kaisers nachziehen soll (vgl. 1.506 Talibus edictis urbs informata ... eqs.). Der Redner erscheint darin weniger als Gesetzgeber denn als Lehrer. Er appelliert an den Patriotismus der römischen Granden. Die gottgewollte Weltherrschaft Roms wird hier (1.425-432) so aufgefaßt, daß die Herrschaft den Begriff der Überlegenheit über alles Irdische, ja der Entrücktheit von der Welt in sich schließt: cuncta potens mortalia calcas (1.429). Aus dieser Situation ergibt sich die Pflicht, über alles Irdische hinaus den Blick nach oben zu richten, das heißt: die Gottheit nicht unten, nicht im Diesseits, zu suchen; die Erwählung Roms zur Herrschaft über die Welt verlangt eine Religion, die die Welt transzendiert. Das ist eine Forderung des decorum (1.430 Non decet... eqs.). In einem zweiten Anlauf (1.455-46o) wird die Pflicht zur Annahme des Christentums aus der zivilisatorischen Leistung Roms abgeleitet; auch sie ist

11 Prudentius, Contra Symmachum 1.33f.: Estne ille e numero paucorum, qui diadema Sortiti aetheriae coluerunt dogma sophiae? Die Polemik gegen das Ideal Platons (Politeia 5.473 C-E) bei Lactanz, Divinae institutiones 3.21.6 macht klar, daß mit der formalen Bestimmung einer Einheit von Philosophie bzw. Weisheit und Macht noch nichts gesagt ist, wenn nicht feststeht, was ,Weisheit' eigentlich ist. In der Formulierung bei Prudentius scheint Cicero, Epistulae ad Quintum fratrem 1.1.29 benutzt, wo die zwei Begriffe sapientia und salus begegnen, die dem Dichter (Contra Symmachum 1.29. 32. 34. 36) wesentlich sind: hanc coniunctionem videlicet potestatis ac sapientiae saluti censuit (sc. Plato) civitatibus esse posse. Die griechischen Wörter dogma sophiae geben der Sache aber anderes Gewicht, lassen den Bezug auf Gott und auf Christus (vgl. 1 Cor. 1:24; 30) durchscheinen. 
ein Gebot der dignitas. Rom hat den unterworfenen Völkern Recht und Gesetz gegeben, hat dadurch der ganzen Oikumene eine Milderung der wilden Formen des Kriegs und des Lebens gebracht, und deshalb ist es unwürdig $\left(1.45^{8}\right.$ Indignum ac miserum est ... eqs.), wenn Rom sich in Sachen der Religion die unvernünftige Denkungsart wilder Völker zu eigen macht. Denn heidnischer Götterkult ist barbarisch, was durch die voraufgehende Schilderung (1.433454) des Kults nach seinen verächtlichen Gegenständen, seinem Motiv (der Angst) und seiner Praxis (dem wüsten, blutigen Opferschmaus) begründet wurde. Als drittes Argument wird die historische Erfahrung angeführt (1.461500). Rom muß das Zeichen des Kreuzes anerkennen, das der Kaiser als Feldherr, Gesetzgeber und Triumphator in Rom führt; denn unter diesem Zeichen hat einst Constantin die Stadt von der Tyrannei des Maxentius befreit. Und das ist eine Erfahrung, die gerade die Senatoren machten, die vom Willkürregiment des Tyrannen besonders betroffen waren. Damals warfen sie sich dem Sieger zu Füßen und huldigten Christus, dessen Name auf den Waffen des Siegers leuchtete. Darin liegt der Appell, aus der Erfahrung zu lernen. Es ist das hier übrigens die einzige Erwähnung Constantins im Werk des Prudentius, der sonst überall hinter Theodosius zurücktritt. Die Rede endet mit der Aufforderung (1.501-505), die Götterbilder vom Blut der Schlachtopfer, mit dem sie bespritzt sind, zu reinigen und diese Werke großer Meister zum Schmuck der Stadt aufzustellen. Das ist ein Symbol christlichen Kulturwillens, vorgebracht in Anrede an die Senatoren, die proceres (502). Damit ist für alle Kunstrichtungen, für alle Bildungsgüter festgestellt, daß die Conversion zum Christentum eine Reinigung, Veredelung, Erhöhung der Kulturschätze bringen soll. Und damit ist das innerste Motiv der heidnischen resistenza getroffen, der es im Grunde um die Kultur ging, nicht um eine bestimmte Religion, oder um die Religion nur insoweit, als sie Teil der Kultur war. ${ }^{12}$

\section{$7 \cdot$}

Es lag in der Konsequenz der dramatischen Gestaltung des Buchs, daß die Peripetie eine radikale Veränderung der religiösen Zustände in Rom auslösen

Die Prudentiusverse Contra Symmachum 1.501-505 scheinen vorwegzunehmen, was das kaiserliche Edikt vom 29. Januar 399 verfügte: sicut sacrificia prohibemus, ita volumus publicorum operum ornamenta servari (Codex Theodosianus 16.10.5). Zur Interpretation dieser Verse und der Parallelstelle Prudentius, Peristephanon 2.481-484, siehe Christian Gnilka, Chrêsis II. Kultur und Conversion (Basel, 1994), pp. 146-50, zum Terminus ornamenta Christian Gnilka, Prudentiana II. Exegetica (Basel, 2001), pp. 304-12. 
mußte. Das heißt: die Theodosiusrede mußte ein Erfolg sein. Ihr positives Ergebnis wurde aber dadurch geschmälert, daß die Senatoren um Symmachus, also gerade die eigentlichen Adressaten des Protreptikos, vom Auftreten des Kaisers im Senat sich nicht hatten beeindrucken lassen. Prudentius versucht im Schlußteil des Gedichts, dem ungünstigen Eindruck dieser Tatsache entgegenzuwirken. Zu diesem Zweck setzt er verschiedene Mittel ein: 1) Er betont mehrmals, bei den verstockten Heiden handele es sich nur um eine kleine Gruppe. Die Mehrheit der Senatoren verlange nach der Taufe und eile zu den christlichen Basiliken (1.544-551); eine Liste der Namen berühmter Adelsgeschlechter soll bezeugen, daß die Conversion die Spitzen der Gesellschaft erfaßt habe (1.552-568). Im Volk beobachtet der Dichter dieselbe Begeisterung: alles strömt zum Petrusgrab am mons Vaticanus und zum Baptisterium bei der Lateransbasilika (1.578-586). Es entsteht der Eindruck einer großen Volksbewegung, die alle Zweifler mitreißen soll. 2) Die Conversion wird aus einem tiefen und echten Wandel der Gesinnung erklärt: Rom geht zum Glauben an Christus über pleno amore (vgl. 1.523); aller Denken richtet sich auf die Ewigkeit (1.510; 559f.; 587-590). Jetzt endlich erkennt und bereut man auch das schwere Unrecht der blutigen Christenverfolgungen (1.511-523). Der Dichter sieht offenbar erst durch diese Änderung des öffentlichen Bewußtseins die Verfolgungen als wirklich beendet an. Andere Stellen in seinem Werk bestätigen diesen Eindruck. ${ }^{13}$ Daran zeigt sich wieder, wie er bemüht ist, Theodosius über Constantin zu stellen, wieviel mehr ihm sein Kaiser gilt. 3) Der militärische Sieg am Frigidus bleibt im Hintergrund: Der Triumph über „die beiden Tyrannen" - Eugenius und Arbogastes sind gemeint ${ }^{14}$ - wird nur zweimal kurz gestreift (1.410; 462f.), hoch gepriesen wird dagegen der Sieg, den Theodosius als triumphator togatus errang (1.524-540): der Sieg nicht über sichtbare Gegner, sondern über unsichtbare (vgl. 1.538), nicht über Menschen, sondern über Dämonen. Dem Sieg in der Schlacht soll auf diese Weise das odium genommen werden, das er im Herzen eines Symmachus gewiß erregte; er wird in seiner Folge betrachtet, die der Dichter als Rettung aus schlimmster, aus geistlicher Gefahr begreift und empfiehlt. Die Verse sind hochrhetorisch, sie geben aber den Blick frei auf den ernsten und tiefen Grund des Kampfs, den Prudentius gegen jede Wiederbelebung heidnischen Kults führte (vgl. 1.1-8). Will man dem Autor gerecht werden, muß man diesen Grund für ihn selbst gelten lassen.

13 Vgl. besonders Prudentius, Contra Symmachum 2.678ff.: Hac me labe ream modo tempora vestra piarunt... eqs. (Rede der Roma an die Theodosiussöhne).

14 Nicht Maximus († 388) und Eugenius, wie gemeinhin angenommen wird. Eine Begründung muß ich mir hier ersparen. 
4) Jeglicher Hauch gesetzlichen Zwangs schwindet schon angesichts der Begeisterung Roms für das Christentum, die der Dichter in seinen Versen einzufangen sucht. Ausdrücklich wird aber auch die praktische Toleranz des Kaisers betont, der Heiden wie Symmachus in höchste Ehrenämter hebt (1.611623). Was Prudentius dazu vorbringt, bestätigt der heidnische Rhetor Libanios, der sich in seiner Rede pro templis mit folgenden Worten an Theodosius wendet: ${ }^{15}$ "Ja, du hast tatsächlich die Vertreter dieser Religion nicht einmal von den Ehrenstellen ausgeschlossen, sondern ihnen sogar Machtpositionen gegeben und sie zu deinem Tischgenossen gemacht - und dies viele Male - und auf ihr Wohl getrunken ..." usw.

Indem Prudentius diese Seite der kaiserlichen Religionspolitik hervorkehrt, gelingt es ihm, auch die Fortdauer einer gewissen resistance unter den Senatoren in den Dienst seines Protreptikos zu stellen, also aus der Toleranz des christlichen Herrschers eine Paränese zu machen.

\section{8.}

Liest man das erste Buch Contra Symmachum, könnte es fast so scheinen, als habe es das Christentum in Rom vor Theodosius nicht gegeben oder als habe es dort zumindest keine Wirkung gehabt. Die Märtyrer erscheinen nur als Opfer, nicht als Vorkämpfer ihrer Religion (1.514-523). Man sieht daran, wie das Buch als Mahnschrift auf die Geisteshaltung des Symmachuskreises Rücksicht nimmt. Im Laurentiushymnus entwickelt der Dichter eine andere Schau der Christianisierung Roms. Hier läßt er den Märtyrer von der dämonenabwehrenden Kraft der Apostelgräber sprechen (Peristephanon 2.457-472) und stellt fest, daß mit der Passion des hl. Laurentius der Niedergang des Götterkults in Rom einsetzte (Peristephanon 2.489-500). Aber es bleiben auch hier gewisse Konstanten seines Geschichtsbilds. Das vortheodosianische Rom ist nicht christlich und steht in dieser Hinsicht hinter der schon christianisierten Oikumene zurück (Peristephanon 2.433-444), so daß der Märtyrer betet: „Gib, Christus, deinen Römern, daß ihre Stadt christlich sei, durch die du bewirkt hast,

15 Libanios, Orationes 30.35. Übersetzung: Heinz-Günther Nesselrath, in Für Religionsfreiheit, Recht und Toleranz, eds. Rainer Hirsch-Luipold, Reinhard Feldmeier, Heinz-Günther Nesselrath, Sapere 18 (Tübingen, 2011), 42ff., hier 75. Die Parallele bei Libanios beweist, daß nicht jede Äußerung des panegyrischen Dichters falsch sein muß, beweist aber auch, wie verschieden derselbe Befund gedeutet werden kann. Libanios zieht aus der praktischen Toleranz des Kaisers den merkwürdigen Schluß, daß heidnische Religion nicht so schlimm sein könne. 
daß alle anderen in Sachen der Religion ein und dieselbe Überzeugung haben!" (Peristephanon 2.433-436). Und weiter: auch hier ist es erst Theodosius, nicht etwa Constantin, der Abhilfe schafft. Der Märtyrer schaut den künftigen Princeps, der die Tempel schließen wird, und kündet von den Götterbildern in Marmor und Bronze, die dann, von Blut gereinigt, als Kunstwerke dastehen werden (Peristephanon 2,481-484). Daß Prudentius dieses Motiv wiederholt, zeigt, wie wichtig es ihm als Symbol christlichen Kulturwillens war. Man hat treffend bemerkt, ${ }^{16}$ der Zeitgenosse des Dichters habe bei der Lektüre des Hymnus Verkündigung und Erfüllung in einem erlebt - wie einst der Zeitgenosse Vergils, der in der Aeneis las, wie Jupiter die Herrschaft des Augustus voraussagt (Aeneis 1.286-296). Aber Prudentius schildert diese Erfüllung dann auch in mehreren Strophen (Peristephanon 2.509-528), indem er aus der Zeit des Märtyrers heraustritt und in die eigene, die theodosianische, wechselt.

9.

Das Erste Buch Contra Symmachum ist ein Rombuch, und das in konkretem Sinne. Es geht darin um die Zustände in der Stadt Rom. Die Stadt ist gegenwärtig durch ihre Topographie, durch ihre Tempel und Basiliken, Straßen und Amphitheater. Aber Rom bildet darüberhinaus im allgemeinen Bewußtsein das historische Zentrum des Reichs, der Name steht als Inbegriff für alles, was das Reich bedeutet, und Prudentius teilt diese Auffassung. Es wäre daher seltsam, sollte der tiefgreifende Wandel, den er sieht und den er als Vollendung einer weltumspannenden Erneuerung begreift, ohne Wirkung auf seine Romidee geblieben sein. ${ }^{17}$ Welcher Art diese Wirkung ist, zeigt er durch Aufnahme der berühmten Worte Jupiters bei Vergil: His ego nec metas rerum nec tempora pono, / imperium sine fine dedi (Aeneis 1.278-9). An die Stelle Jupiters tritt bei Prudentius der Kaiser: Denique nec metas statuit nec tempora ponit, / imperium sine fine docet (1.541-2). Aber Theodosius kann nicht geben, was Jupiter bei Vergil gibt und nach christlicher Überzeugung nur Gott geben kann, und so

16 Vinzenz Buchheit, "Christliche Romideologie im Laurentiushymnus des Prudentius," in P. Wirth (ed.), Polychronion. Festschrift für Franz Dölger (Heidelberg, 1966), pp. 121-44 = R. Klein (ed.), Das frühe Christentum im römischen Staat (Darmstadt, 1982²), pp. 455-85, hier 479 .

17 Zum weiteren Hintergrund s. Peterson, Der Monotheismus, passim; Friedrich Klingner, "Rom als Idee", in Ders., Römische Geisteswelt (Munich, 19655), pp. 645-66; Manfred Fuhrmann, "Die Romidee der Spätantike," Historische Zeitschrift 207 (1968), 529-61, mit scharfer Kritik an den „erbaulichen Darstellungen pietätvoller Altertumsbetrachter“ (540-42) und einer wenig kongenialen Behandlung des Prudentius (556-58). 
wird aus Vergils dedi bei Prudentius ein docet. Im Wechsel des Verbums liegt der tiefe Unterschied. Noch ganz im Sinne Vergils kann Claudian sagen: nec terminus umquam / Romanae dicionis erit (De consulatu Stilichonis 3.159-6o), aber Prudentius meint eine geistige propagatio imperii. Die alle Grenzen von Raum und Zeit übersteigende Größe des Reichs ist Ergebnis der Lehre des christlichen Herrschers, das heißt: seiner als Lehre aufgefaßten Religionspolitik. Im berühmten Schlußkapitel des zweiten Buchs der Civitas Dei, das vielleicht durch Prudentius inspiriert ist, ${ }^{18}$ verheißt Augustinus dem Römertum, im himmlischen Vaterland werde es „wahrhaft und auf ewig“ herrschen:(Deus) imperium sine fine dabit. Aber was Augustinus erst für die Ewigkeit verspricht, das bricht nach Prudentius schon jetzt, schon unter Theodosius, an. Theodosius lehrt Rom, „durch eine überirdische Herrschaft auf ewig mächtig zu sein“ (I.540 supero pollere in saecula regno), „die irdische Herrschaft fortan über die Sterne oben am weiten Himmel auszudehnen" (1.589-9o ardua magni / iam super astra poli terrenum extendere regnum). Die Ewigkeit hat für Prudentius schon begonnen. Im Zweiten Buch wird das weiter ausgeführt. Es ist klar, daß wir mit solchen Gedanken die Ebene rein historischer Argumentation verlassen und uns der theologischen oder geschichtstheologischen Betrachtungsweise des Autors anpassen müssen.

10.

Das Zweite Buch ist etwa sieben Jahre nach dem Ersten, wohl im Sommer 402, abgeschlossen. Angeredet werden die Theodosiussöhne, aber auch Theodosius selbst ist darin noch gegenwärtig. Der Form nach gehört das Buch in die Tradition solcher apologetischer Werke, die sich mit einer gegnerischen Schrift auseinandersetzen, indem sie deren Wortlaut aufnehmen. Prudentius nennt das dicta dictis refellere (vgl. II.4). So verfährt Origenes in seinem Werk gegen Kelsos, so später auch Kyrill von Alexandrien in der Schrift gegen Julian. Augustinus lernte diese Methode in seinen Disputationen mit Donatisten und Manichäern kennen und schätzen und übertrug sie in sein apologetisches Schrifttum. ${ }^{19}$ Prudentius setzt sich so mit der berühmten Relatio des Symmachus auseinander, die der Stadtpräfekt fast zwanzig Jahre früher (384) in

18 Klingner, Rom als Idee, p. 663. Zustimmend Franz Georg Maier, Augustin und das antike Rom, Tübinger Beiträge zur Altertumswissenschaft 39 (Stuttgart, 1955), p. $101 \mathrm{mit}$ Anmerkung 59. Maier betont jedoch mit Recht den Unterschied: die patriotischen Gefühle des Dichters teile Augustinus nicht.

19 Vgl. Christian Gnilka, Prudentiana II, p. 27of. 
Sachen des Victoriaaltars vorgebracht hatte. Die dichterische Wiedergabe der gegnerischen Sätze ist freilich eine selbständige Leistung, die bereits dem eigenen Beweisziel dient. Zu den Argumenten des Gegners gehört die bekannte Behauptung, der Erfolg spreche für die alten Götter (Symmachus, Relationes 3.8; Prudentius, Contra Symmachum 2.488f., vgl. 2.564f.). Prudentius versteht sehr wohl, daß damit die Weltherrschaft Roms gemeint sei $(2.578 / 82)$ und nennt den wahren Grund: dieser Erfolg werde dem Willen Gottes verdankt, der die Welt unter der Herrschaft Roms einigen wollte. Was dann bei Prudentius folgt (2.586ff.), kann man das hohe Lied der Concordia nennen: Nichts ist Gott so verhaßt wie Zwietracht (2.593-597), alle Völker, die der Zivilisation aufgeschlossen sind, sollten daher unter einer milden Herrschaft geeint werden, mit dem Ziel, daß die Herzen der Menschen in der Liebe zur Religion zusammenstimmten; denn nur solche geistige Einheit der Nationen ist Christi würdig (2.586-592) - würdig der Ankunft Christi in der Welt (2.634f.). Diese vollkommene Einheit ist jetzt erreicht (Anaphora des nunc betont den zeitlichen Aspekt: 2.614-616). Gott hat die Kriege, die auf der ganzen Welt tobten, beendet, indem er die Menschen aller Nationen lehrte, das Haupt unter dieselben Gesetze zu beugen und Römer zu werden (2.598-607). Es herrscht völlige Rechtsgleichheit, alle leben zusammen wie in derselben Vaterstadt oder im selben Vaterhaus. Gerichtsbarkeit, Handel, Eherecht überwinden alle Grenzen: aus verschiedenen Nationen entsteht sanguine mixto ein einziges Geschlecht (2.608-618).

11.

Das alles sind bekannte Motive der laudes Romae. Sie kommen von weither, begegnen in der Zeit unseres Dichters auch bei Claudian und, wenig später, bei Rutilius Namatianus. ${ }^{20}$ Aber Prudentius gibt ihnen eine neue Richtung. Lehrreich ist ein Vergleich mit Eusebius. Er hat, Gedanken seines Lehrers Origenes aufgreifend, die Romidee besonders entwickelt: die römische Monarchie und die Lehre Christi sind zwei große Mächte, die gleichzeitig auftraten, zur Blüte gelangten und die ganze Welt befriedeten; die Monarchie beseitigte die Vielherrschaft der Nationalstaaten und damit die Grundlage des Polytheismus und der Kriege, erleichterte auch die christliche Verkündigung; die Herrschaft des Einen Gottes hob die Vielherrschaft der Dämonen auf und so auch die Ursache

20 Claudian, De consulatu Stilichonis 3.154-161; Rutilius Namatianus, De reditu suo 1.63-66, erklärt von Ernst Doblhofer, Rutilius Claudius Namatianus, De reditu suo 2 (Heidelberg 1977), pp. 48-5o. Vgl. noch Libanios, Orationes 59.171. 
der Zersplitterung der Menschheit. ${ }^{21}$ „Zum Imperium Romanum, das die Nationalitäten auflöst, gehört metaphysisch der Monotheismus. Was aber prinzipiell mit Augustus angefangen hat, das ist in der Gegenwart unter Konstantinos Wirklichkeit geworden“. ${ }^{22}$ Auch nach Prudentius geschah die Einigung und Befriedung der Welt mit dem Willen Gottes. Aber diesen geschichtlichen Prozeß sieht er nur als Vorbereitung eines Zustands an, der erst in theodosianischer Epoche erreicht wurde, und dieser Zustand, die totale Concordia, ist seinerseits Voraussetzung für die Ankunft Christi in der Welt. Die ganze Entwicklung ist also zentriert auf einen neuen Eintritt Christi in die Geschichte, auf eine Parusie, die weder mit der ersten identisch ist, mit der Inkarnation, noch mit der zweiten am Ende der Zeiten. ${ }^{23}$

12.

Daher treten bei Prudentius Momente zurück, die für Eusebius wichtig sind: das gleichzeitige Erscheinen zweier Dynameis, der Monarchie und des Evangeliums, ihr wechselseitiges Zusammenwirken und dessen Vollendung unter Konstantin: das alles muß fortfallen, weil der Dichter den Blick auf ein anderes Ziel richtet. ${ }^{24}$ Am besten hört man ihn selbst (II.619-640):

„Das ward erreicht durch die großen Erfolge und Triumphe des römischen Reichs; der Ankunft Christi wurde schon damals, glaub` mir, der Weg gebahnt;

Hauptstellen: Eusebius, Laus Constantini 16.5-7 (GCS 1, p. 249,26-250,29 Heikel); Praeparatio evangelica I, p. 4.2-5 (GCS Euseb. 8/1:14,19-16,8 Mras); Demonstratio evangelica III.7.30-35 (GCS Euseb. 6, p. 145,21-146,17 Heikel); ibid. viI.2.21f. (p. 332,4-19); VIII.4.11-13 (p. 396,15-397,4); Theophania Syr. III.2 (GCS Euseb. 3/1:127*, 12-128*, 20 Gressmann). Peterson, Der Monotheismus, p. 78.

23 Das trotz aller traditionellen Elemente doch Neue und Eigenartige dieser geschichtlichen Vision hat Klaus Thraede richtig empfunden, allerdings mit allerlei kritischen Anfragen an den Dichter verbunden: Klaus Thraede, "Concordia Romana in der Antwort des Prudentius auf die dritte Relatio des Symmachus," in Tesserae. Festschrift Josef Engemann, eds. J. Engemann, E. Dassmann, K. Thraede, Jahrbuch für Antike und Christentum, Ergänzungsband 18 (Münster, 1991), pp. 380-94, besonders 392f.

24 Zwar findet auch für Prudentius die römische Verfassungsgeschichte in der Monarchie ihren Endpunkt und Höhepunkt, aber diese politische Entwicklung bildet bei ihm nur einen Grund dafür, daß auch in der Religion schließlich der Übergang zum Guten und Richtigen erreicht werden müsse (Contra Symmachum II.413-440), dient also seinem protreptischen Anliegen. Der verfassungsgeschichtliche Abriß bei Prudentius ist durch ein Großinterpolament schwer gestört: Contra Symmachum I [423-427]. Vgl. Christian Gnilka, "Römische Verfassungsgeschichte bei Prudentius und Ampelius," Hermes 140 (2012), 448-56. 
seit langem ebnete ihn unseres Friedens allgemeiner Freundschaftsbund unter der Leitung Roms. Denn welchen Platz hätte Gott finden können in einer Welt voller Wildheit und in Menschenherzen voll von Zwietracht, die ihr Recht zu wahren suchten bald aus diesem, bald aus jenem Grunde, wie das vormals war? So steht es, wenn die Regungen in der Brust des Menschen ungeordnet und die Seelenteile in gestörter Harmonie uneins sind: die lautere Weisheit naht sich nicht, Gott kehrt nicht ein. Doch wenn der Fürst, der Geist, sein Recht der Herrschaft erlangt, des streitlustigen Leibes Stöße und die widerspenstigen Fasern zügelt, alles Fleisch allein durch die Vernunft im Zaume hält, dann gewinnt das Leben festen Stand, das Denken Sicherheit, faßt er mit dem Herzen Gott und unterwirft sich Ihm als alleinigen Herrn. Wohlan, Allmächtiger, komm! Ströme herab in die einträchtigen Lande! Nun faßt Dich, Christus, die Welt, die Pax und Roma mit einigendem Bande umschlingen. Haupt und Gipfel der Dinge sind sie auf Dein Geheiß. Rom erlangt Dein Wohlgefallen nicht ohne den Frieden, und daß der Friede gefällt, macht die Erhabenheit Roms, das den mannigfachen Aufruhr mit Macht in Schranken weist und zugleich durch Schrecken niederhält."

Concordia und pax sind also Bedingungen der Gegenwart Christi; in der Welt wie im Einzelmenschen. Die göttliche Sapientia (Christus) nimmt nur dann Wohnung im Menschen, wenn mens, d.h. die Seele, die Herrschaft erlangt und die widerspenstigen Kräfte des Leibes besiegt hat, desgleichen ist die durch christliche Eintracht geläuterte Pax Romana die Bedingung für die Einkehr Christi auf Erden. Der Dichter gibt uns mit dieser Analogie einen Hinweis auf das Werk, in dem wir seine Vision der Geschichte, die sich hier nur in einem ihrer Teile zeigt, vollständig entwickelt finden.

13.

Die Psychomachie schildert den Kampf der Seele, den die Tugenden gegen die Laster führen. Aber das Gedicht ist in gewisser Weise auch ein geschichtliches Epos. ${ }^{25}$ Denn die Psychomachie spielt sich auch auf der Ebene der Geschichte ab, und das in mehrfacher Hinsicht. Vorgebildet ist sie in dem Krieg, den Abraham zur Befreiung Lots führte - das ist das Thema der Praefatio; Fides tötet im ersten Zweikampf die veterum Cultura deorum und krönt die Märtyrer; Discordia, die ein heimtückisches Attentat auf Concordia verübt, gibt sich als Häresie

25 Dazu Christian Gnilka, "Die Bedeutung der Psychomachie im Gesamtwerk des Prudentius," in, Seelengespräche, eds. Beatrice B. Jakobs, V. Kapp, Schriften zur Literaturwissenschaft 31 (Berlin, 2008), pp. 19-39, hier 29-34. 
zu erkennen; die Laster erscheinen als barbarische Störenfriede. Alle diese Dimensionen der Schlacht: die Kämpfe der Seele gegen die Laster, die Kämpfe Altisraels gegen seine Feinde, die Kämpfe des Christentums gegen den Götzendienst, der Kirche gegen die Irrlehren, die Kämpfe Roms gegen die Störer der pax Romana - sie alle faßt Prudentius in einer Synopse zusammen, sie alle laufen auf ein gemeinsames Ziel zu, das der Dichter in dem endzeitlichen Bilde des himmlischen Jerusalem erblickt, wo Sapientia auf ewig thront. Blickt man von hier aus auf die besprochene Passage des Zweiten Buchs Contra Symmachum, erkennt man Ähnlichkeit und Verschiedenheit. Die pax Romana theodosianischer Zeit ist nicht identisch mit dem Zustand der ewigen Friedensherrschaft; denn wie der Kampf der Seele im Diesseits nicht endet, so auch nicht der politische und militärische. Die pax Romana muß sich gegen ihre Widersacher unausgesetzt behaupten, wofür der Gotenkrieg des Jahres 402 gleich ein Beispiel bietet (2.696-759). Aber wenn der Dichter in seiner Zeit eine innere und äußere Einheit der Oikumene hergestellt sieht, die es möglich macht, daß die göttliche Sapientia auf die Welt herabkommt, dann scheint er doch eine Art Vorstufe oder Vorbereitung jenes endgültigen Friedens wahrzunehmen. In der Peterskirche las Prudentius die Bogeninschrift, die Christus anredet (ICUR 2.4092 = ILCV 1752):

Quod duce te mundus surrexit in astra triumphans, hanc Constantinus victor tibi condidit aulam.

"Weil unter Deiner Führung die Welt triumphierend sich zu den Sternen erhob, erbaute Dir Constantius nach dem Sieg diese Halle."

Was diese Stifterinschrift für Constantin in Anspruch nimmt, sieht Prudentius unter Honorius verwirklicht und überboten (II.758-9). Roma spricht:

Regnator mundi Christo sociabere in aevum, quo ductore meum trahis ad caelestia regnum.

"Als Herrscher der Welt wirst du (Honorius) auf ewig an Christi Seite stehen: unter Seiner Führung ziehst du mein Reich zum Himmel empor."

Hier wird eine Art Gottesherrschaft verkündet, an der Honorius teilhat.

14.

Wir wissen alle, wie grausam der Dichter durch den Gang der Ereignisse enttäuscht wurde - falls er sie noch erlebte. Er entwirft ein Idealbild, aber er war 
sich dessen sicher bewußt. Die äußeren Gefahren, die anhaltenden Glaubenskämpfe und die Spannungen zwischen den beiden Reichsteilen, wie sie etwa das Werk Claudians bezeugt, können einem Manne wie Prudentius nicht verborgen geblieben sein. Ein Panegyrikos ist ja selten nur Lob, oft enthält er Züge der Mahnung. Und so scheint in dem enthusiastischen Preis der concordia bei Prudentius auch eine geheime Sorge mitzuklingen, scheint sein Protreptikos über den Kreis des Symmachus hinaus viel größere Reichweite zu beanspruchen. Aber die Geschlossenheit seines Entwurfs hat etwas Großes an sich. Die mehrfachen Versuche in der abendländischen Geschichte, eine Regeneratio imperii zu entdecken, sprechen für ihn. Und allen modernen Versuchen, eine völkerumspannende, vielleicht gar globale Friedensherrschaft $\mathrm{zu}$ errichten, lassen gerade das vermissen, was seine Vision groß macht: das Hinausschauen über alles Zeitliche, die Überzeugung, daß die Einheit stiftende Kraft nicht allein aus der Politik gewonnen werden kann.

\section{Bibliography}

Vinzenz Buchheit, "Christliche Romideologie im Laurentiushymnus des Prudentius," in

P. Wirth (ed.), Polychronion. Festschrift für Franz Dölger (Heidelberg, 1966), pp. 121-44

= R. Klein (ed.), Das frühe Christentum im römischen Staat (Darmstadt, 1982 2 ), pp. $455^{-85}$.

Erich Burck, Die Erzählkunst des T. Livius (Berlin, 1964²).

Alan Cameron, "Theodosius the Great and the Regency of Stilico," Harvard Studies in Classical Philology 73 (1969), 247-80.

Altay Coşkun, “Zur Biographie des Prudentius," Philologus 152 (2008), 294-319.

Ernst Doblhofer, Rutilius Claudius Namatianus, De reditu suo II (Heidelberg, 1977).

Raffaele Farina, L'impero e l'imperatore cristiano in Eusebio di Cesarea (Zürich, 1966).

Manfred Fuhrmann, "Die Romidee der Spätantike," Historische Zeitschrift 207 (1968), 529-61.

Edward Gibbon, The History of the Decline and Fall of the Roman Empire. A new edition. Vol.3 (London, 1823).

Christian Gnilka, Chrêsis II. Kultur und Conversion (Basel, 1994).

- Prudentiana I. Critica (Munich, 2000).

-, Prudentiana II. Exegetica (Basel, 2001).

—, "Die Bedeutung der Psychomachie im Gesamtwerk des Prudentius," in Seelengespräche, eds. B. Jakobs, V. Kapp (Berlin, 2008), pp. 19-39.

— , "Römische Verfassungsgeschichte bei Prudentius und Ampelius," Hermes 140 (2012), 448-56.

Richard Heinze, Virgils epische Technik (Leipzig, 1914²Darmstadt, 19574). 
Friedrich Klingner, “Rom als Idee,” in Römische Geisteswelt, F. Klingner (Munich, 19655), 645-66.

Franz Georg Maier, Augustin und das antike Rom (Stuttgart, 1955).

Heinz-Günther Nesselrath, in: Für Religionsfreiheit, Recht und Toleranz, eds. R. HirschLuipold, R. Feldmeier, H.-G. Nesselrath (Tübingen, 2011).

Erik Peterson, Der Monotheismus als politisches Problem (Leipzig, 1935).

Klaus Thraede, "Concordia Romana in der Antwort des Prudentius auf die dritte Relatio des Symmachus," in Tesserae. Festschrift Josef Engemann, eds. J. Engemann, E. Dassmann, K. Thraede (Münster, 1991), pp. 380-394. 